\title{
Situational Interest and Actualized Individual Interest: Two Problematic Constructs
}

\author{
David Palmer \\ School of Education, University of Newcastle, New South Wales, Australia \\ Email: david.palmer@newcastle.edu.au
}

\begin{abstract}
Interest is currently thought to be an important construct that it can influence student motivation. It has widely been recognized that there are long-term and short-term forms of interest (often referred to as individual interest and situational interest, respectively), but it has not always been recognized that these may interact. For example, the term actualized individual interest can be used to refer to the arousal of interest that occurs when educational material aligns with one's preexisting individual interest. This form of interest is important because it results in high level and persistent engagement in learning, yet it is not a widely studied phenomenon. The purpose of the present commentary is to bring attention to this important construct, with the aim of promoting conversation among researchers.
\end{abstract}

Keywords: individual interest, situational interest

\section{Introduction}

Interest, which has been described as "the persisting desire to engage with certain content" (Cromley, Perez, \& Kaplan, 2015, p. 3) has been found to be a key predictor of student motivation and performance. For example, Maltese, Melki, and Wiebke (2014) surveyed college and university students and found that it was their interest and passion for the field of study that was most often critical for their persistence at college. Similarly, Thoman, Arizaga, Smith, Story, and Soncuya (2014) reported that declines in interest played a major role in attrition from college programs.

Interest has several characteristics (Renninger \& Hidi, 2011). First, it always occurs in relation to particular content, ideas, activities, or events. Second, it involves an interaction between an individual's personal characteristics and the environment. Yet interest is not an unproblematic construct: There are long-term and short-term forms of interest, and these have identifiable subcomponents. Thus, a researcher might ask a student whether he or she is interested in a particular thing, but the actual type of interest or the relative importance of each of the subcomponents would still be open to question. These issues are discussed below.

\section{Long-term and Short-term Forms of Interest}

A person might have a long-term interest in (say) astronomy, but might also be momentarily interested in an unusual or novel event that is not related to astronomy. The long-term form of interest has been referred to as either individual interest (Renninger \& Hidi, 2016) or personal interest (Krapp, 2002; Schiefele, 1999), whereas the momentary form of interest has been referred to as situational interest (Renninger \& Hidi, 2016). Some researchers have proposed a third form of interest called topic interest, but there has been little consensus as to how it should be conceptualized (Trend, 2005), so its significance is an open question (it should be noted that topic interest was not included as a component of Hidi and Renninger's [2006] model of interest development, so it will not be further considered here).

The four-phase model proposed by Hidi and Renninger (2006) described a developmental trajectory in which situational interest may develop into individual interest. Triggered situational interest (Phase 1) is a transient state that is primarily sparked by environmental stimuli such as incongruous or surprising information. Maintained situational interest (Phase 2) involves focused attention and persistence over an extended episode. It is induced by learning environments that provide meaningful tasks and opportunities for active engagement. Emerging individual interest (Phase 3) is primarily self-generated, 
and signals the beginning of an enduring predisposition in which the student comes to value the new content/task and begins to seek repeated reengagement with it. Well-developed individual interest (Phase 4) is self-generated, and refers to higher levels of positive feelings and value, in which the student continues to seek out opportunities to reengage with the content/task, leading to effortless persistence. Previous studies have tended to support the developmental relationship between situational interest and individual interest (Randler \& Bogner, 2007; Rotgans \& Schmidt, 2017).

Individual interest (represented by Phases 3 and 4 in Hidi and Renninger's [2006] model) is particularly worthy of study since it is a powerful motivator for ongoing learning. Hidi (1990) stated that individual interest is a personal preference that tends to be strong, stable, and relatively focused. It involves stored knowledge (cognitive representations from past experience) and stored value (including feelings of competence). Individual interests are motivating, because students who are interested in the material tend to maintain high levels of engagement for longer periods of time and to seek out opportunities to re-engage (Hidi \& Harackiewicz, 2000). In addition, brain studies have found that students find it easier to learn content that interests them and that this content is encoded more strongly in memory (Gruber, Gelman, \& Ranganath, 2014). Similarly, Renninger and Hidi (2016) have argued that enhanced content knowledge is an outcome of individual interest. Consequently, individual interest is known to have powerful effects on learning behaviors and meaningful learning (Durik, McGee, Huber, \& Witers, 2011; Linnenbrink-Garcia, Pugh, Koskey, \& Stewart, 2012; Randler \& Bogner, 2007).

\section{$3 \quad$ Actualized Individual Interest}

An important characteristic of individual interests is that they can become situationally activated, on occasion. Swarat, Ortony, and Revelle (2012) stated, "when people with certain individual interest encounter a situation that matches the particular interest, their individual interest is actualized" (p. 518). Under these conditions, the student experiences a state of high interest leading to effortless engagement in learning. The term actualized individual interest (actualized II) has been used to refer to this situation. This is an active state of interest, so it has some features in common with situational interest. However, actualized II is primarily due to one's individual interest, so it is theoretically distinct from the two forms of situational interest (triggered SI and maintained SI), which are primarily due to situational factors. Also, in cases of actualized II, the interest level should be expected to persist for an extended learning episode, as long as the content continues to relate to the individual interest. This is in contrast to triggered situational interest, in which there can be short-lived fluctuations in interest from moment to moment, but without necessarily creating a meaningful connection to the content (Dohn, 2013).

One problem however, is that actualized II and situational interest can appear to be very similar, because in both cases the student would give the impression of being highly interested. Swarat et al. (2012) reported that, in empirical studies, it is difficult to distinguish between interest that is simply a short-lived reaction and interest that is an activation of a stable interest. As a result, previous authors have not attempted to differentiate between the two. Yet Studies have shown that, at least under experimentally manipulated conditions, students' individual interest can affect their aroused interest during classroom tasks (Durik \& Matarazzo, 2009; Tapola, Veermans, \& Niemivirta, 2013), but very little is known about the characteristics of actualized II as a distinct phenomenon in authentic educational settings. The implication of this is that researchers should, in future, attempt to distinguish between on the one hand, short-term interest that results mainly from situational factors such as novelty, and on the other hand, short-term interest that results mainly from one's enduring individual interest in that material.

In conclusion, in order to identify the factors that might affect student motivation and achievement, it is not only necessary to understand their ongoing interests in the content, but also the ways in which these interests become activated to motivate learning during their studies. 


\section{References}

1. J. G. Cromley, T. Perez, and A. Kaplan (2015), Undergraduate STEM achievement and retention: Cognitive, motivational, and institutional factors and solutions. Policy Insights from the Behavioral and Brain Sciences, 18 .

2. N. B. Dohn (2013), Situational interest in engineering design activities. International Journal of Science Education, 35, 2057-2078.

3. M. Durik and K. L. Matarazzo (2009), Revved up or turned off? How domain knowledge changes the relationship between perceived task complexity and task interest. Learning and Individual Differences, 19, 155159.

4. A. M. Durik, S. McGee, L. Huber, and J. Witers (2011, September), Curiosity, exploration, and the moderating role of individual interest. Poster presented at ESERA 2011, the Biennial Conference of the European Science Education Research Association, Lyon, France.

5. M. J. Gruber, B. D. Gelman, and C. Ranganath (2014), States of curiosity modulate hippocampus-dependent learning via the dopaminergic circuit. Neuron, 84, 486-496.

6. S. Hidi (1990), Interest and its contribution as a mental resource for learning. Review of Educational Research, $60,549-571$.

7. S. Hidi and J. M. Harackiewicz (2000), Motivating the academically unmotivated: A critical issue for the 21st Century. Review of Educational Research, 70, 151-179.

8. S. Hidi and K. A. Renninger (2006), The four-phase model of interest development. Educational Psychologist, 41, 111-127.

9. A. Krapp (2002), Structural and dynamic aspects of interest development: Theoretical considerations from an ontogenetic perspective. Learning and Instruction, 12, 383-409.

10. L. Linnenbrink-Garcia, K. J. Pugh, K. L. Koskey, and V. C. Stewart (2012), Developing conceptual understanding of natural selection: The role of interest, efficacy, and basic prior knowledge. Journal of Experimental Education, 80, 45-68.

11. A. V. Maltese, C. S. Melki and H. Wiebke (2014), The nature of experiences responsible for the generation and maintenance of interest in STEM. Science Education, 98, 937-962.

12. A. Randler and F. X. Bogner (2007), Pupils' interest before, during, and after a curriculum dealing with ecological topics and its relationship to achievement. Educational Research and Evaluation, 13, 463-478.

13. K. A. Renninger and S. Hidi (2011), Revisiting the conceptualization, measurement, and generation of interest. Educational Psychologist, 46, 168-184.

14. K. A. Renninger and S. Hidi (2016), The power of interest for motivation and engagement. New York, NY: Routledge.

15. J. I. Rotgans and H. K. Schmidt (2017), Interest development; Arousing situational interest affects the growth trajectory of individual interest. Contemporary Educational Psychology, 49, 175-184.

16. U. Schiefele (1999), Interest and learning from text. Scientific Studies of Reading, 3, 257-279.

17. S. Swarat, A. Ortony, and W. Revelle (2012), Activity matters: Understanding student interest in school science. Journal of Research in Science Teaching, 49, 515-537.

18. A. Tapola, M. Veermans, and M. Niemivirta (2013), Predictors and outcomes of situational interest during a science learning task. Instructional Science, 41, 1047-1064.

19. D. B. Thoman, J. A. Arizaga, J. L. Smith, T. S. Story, and G. Soncuya (2014), The grass is greener in nonscience, technology, engineering, and math classes: Examining the role of competing belonging to undergraduate women's vulnerability to being pulled away from science. Psychology of Women Quarterly, 38, 246-258.

20. R. Trend (2005), Individual, situational and topic interest in geoscience among 11- and 12-year-old children. Research Papers in Education, 20, 271-302. 